\title{
Exploration of Online Course Construction of Medical Imaging Electronics Synthesis
}

\author{
Xin Bi, Hong Liu, Jiuai Sun, Rui Yang, Wei Li \\ College of Medical Imaging \\ Shanghai University of Medicine \& Health Sciences \\ Shanghai, China \\ E-mail: bix@sumhs.edu.cn
}

\begin{abstract}
This paper states the ideas and methods of the online course construction for the course of medical imaging electronics synthesis. Firstly, the necessity of online course construction is expounded. The online course suited to the students majoring in medical imaging technology is needed. Then, the general idea and features of the curriculum construction are stated. The teaching contents, management system, teaching methods, resources and assement methods are all explored in the construction. Finally, the primary task of the implementation of the curriculum is summarized and a concept is stated that the platform, technology and means should serve the content.
\end{abstract}

Keywords:on line course construction; the course of medical imaging electronics synthesis; the applied technical major for undergraduate

\section{PREFACE}

The course of medical imaging electronics synthesis is a professional basic course for students majoring in medical imaging technology. The major of medical imaging technology is newly established oriented by application technology for undergraduates in our institute. The idea of curriculum construction is different from that of skilled vocational colleges, and it is also different from scientific research oriented undergraduate specialties. It is necessary to cultivate the students' knowledge, ability and quality in a comprehensive and coordinated development. The goal is to cultivating high level applied talents for production, construction, management and other positions. The core is to cultivate students' ability to apply technology in future work. $^{[1]}$ Therefore, in the course of construction, the characteristics of curriculum and students are needed to be considered.

\section{THE NECESSITY OF ONLINE COURSE CONSTRUCTION}

This course includes three parts: electrotechnics, analog electronics, and digital electronics. They are completed in three semesters. The contents and class hours are listed in table 1.

The class hour in each semester is less and the content is more abstract, so it is difficult for students to master. Meanwhile, the relevant knowledge of the course runs through the whole professional course, and its theoretical and practical requirements are very strong. In the teaching process, it is found that there is a lack of solid grasp of the basic knowledge of students and the workload of teachers' teaching and counselling is heavy.

TABLE I. DISTRIBUTION OF CONTENTS AND CLASS HOURS

\begin{tabular}{|c|c|c|c|c|}
\hline Content name & $\begin{array}{c}\text { Theoretical } \\
\text { hours }\end{array}$ & $\begin{array}{c}\text { Experimental } \\
\text { hours }\end{array}$ & $\begin{array}{c}\text { Total } \\
\text { hours }\end{array}$ & semester \\
\hline Electrotechnics & 32 & 16 & 48 & 1 \\
\hline $\begin{array}{c}\text { Analog } \\
\text { electronics }\end{array}$ & 32 & 16 & 48 & 2 \\
\hline $\begin{array}{c}\text { Digital } \\
\text { electronics }\end{array}$ & 32 & 16 & 48 & 3 \\
\hline
\end{tabular}

Therefore, it is of great significance to build the online course to provide students with more opportunities for selfstudy and discussion, to improve students' ability to study independently, to increase communication between teachers and students, and to improve the efficiency of teachers' tutoring.

Different from traditional quality courses and resource sharing courses, the construction of online courses is not only to provide students with different forms of learning materials, but also to improve the learning enthusiasm and initiative by strengthening the learning management, optimizing the content and the flexible discussion and feedback mechanism. ${ }^{[2]}$

\section{THE GENERAL IDEA OF CURRICULUM CONSTRUCTION}

The goal of this online course construction is to serve as a beneficial supplement for students' classroom learning, and assist the classroom learning to complete the students' selfstudy, testing, downloading of learning materials, discussion and other teaching processes.

At present, there are some high-quality online courses on the Internet, although the content and design ideas are very worthy of reference, most of them are courses for engineering majors in first-class research-based engineering colleges, with more class hour and more content. The course of medical imaging electronics synthesis is a unique integrated curriculum in our school. The classroom teaching time of the course is very limited, and a considerable number of students have a weak physical foundation. Therefore, 
more popular, understandable, vivid and targeted resources are urgently needed as supplementary materials for students' learning.

According to the progress of classroom teaching, the timely opening of online courses is conducive to teachers' control of student learning. Therefore, it is necessary to combine the specific conditions of the students and the teaching syllabus for the online course construction, so that it becomes a beneficial complement for the classroom teaching and improve the students' learning effect.

At the same time, the online course construction should also reflect the skills and application of the syllabus, so that our online courses are really suitable to the undergraduates of the applied technical colleges.

In figure 1, the frame of this online course construction is listed.

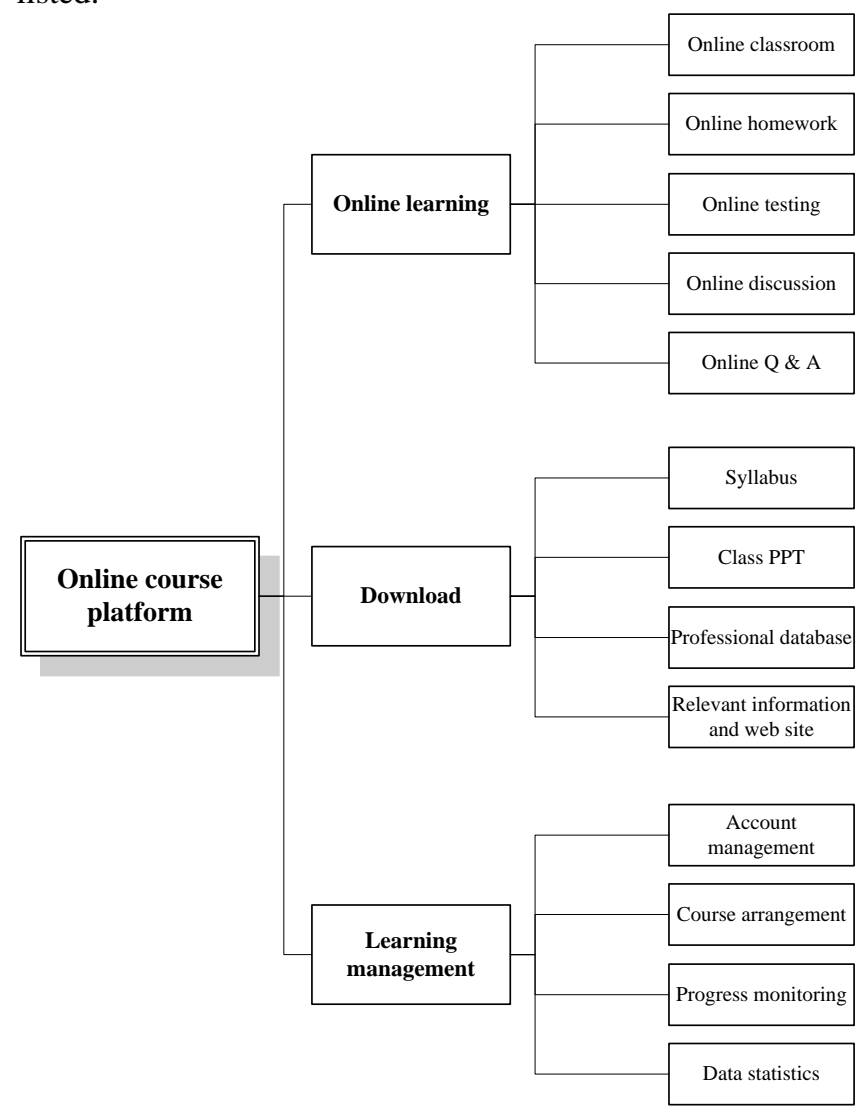

Figure 1. The frame of online course construction

\section{FEATURES OF THE CURRICULUM CONSTRUCTION}

\section{A. The Organic Combination of the three Parts}

Although the three parts of the course are completed in three semesters, the contents are not isolated and are related to each other. Therefore, when recording online course videos, we must fully consider the continuity of student learning.
First of all, the lecture style and the recording style should be unified. Although the three parts are taught by different teachers, they should be as uniform as possible in the details of style, video production, dressing, and speed of speech.

Secondly, for the knowledge point, we should pay attention to the connection between the three parts. In classroom teaching, teachers speak their own contents respectively, and students do not understand the connection of them. Therefore, in the online course construction, before the beginning of a new part of content learning, a teaching video and testing link which play a connection role are created specifically so that students can better integrate knowledge.

Thirdly, three parts of classroom teaching are assessed in three semesters separately. In the construction of online courses, when all the contents of the three parts are completed, comprehensive test questions are set up, and the three parts of the content are combined to assess the students' ability to use knowledge in a comprehensive way.

\section{B. Implementation of the Management System}

A good management mechanism is provided in this online course. For example, an admission system is required for students and a fixed identity and account are used for learning.

Students can use relatively free time to study, but the progress of the study should be based on the requirements of the syllabus. The system can monitor the progress of each student and give timely reminder to students who are slower or behind schedule.

\section{Online Mixed Teaching Method}

Variety of teaching methods can be introduced by using online discussion room.

The PBL (Problem-Based Learning) teaching method is taken as an example here. The offline PBL is moved to online. Teachers submit cases or questions online, and then sufficient time is given to students to collect information, analyze cases, and conduct group discussions online. Teachers summarize the discussions and give learning videos to complete the study of a knowledge point. In this way, students' enthusiasm and initiative to participate in learning are fully mobilized. However, there are high requirements for the design of learning situations.

\section{The Introduction of Professional Database}

The database includes not only the teachers' lesson plans and courseware, but also the circuit diagrams related to the imaging equipment, in which the circuit principle and related knowledge points are indicated.

For example, the transmitting pulse generating circuit in ultrasonic equipment, which contains the LC circuit, field effect tube, diode rectifier circuit and other knowledge points. Therefore, in the teaching of related knowledge points, teachers can link the transmitting pulse generating circuit in the database, and make corresponding explanations. Firure 2 
shows the principle of the transmitting pulse generating circuit in ultrasonic equipment.

In this way, students' learning is not a single line, but a combination of theory and practical application, which can greatly improve the students' practical application skills, and deepen the understanding and mastery of basic knowledge.

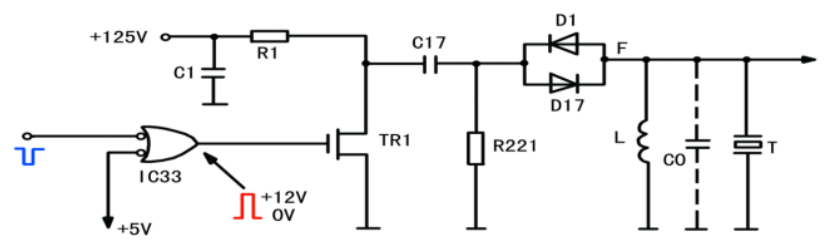

Figure 2. The transmitting pulse generating circuit in ultrasonic equipment

\section{E. Diversification of Assessment Methods}

As an online course, it is not only the extension of the teaching process and the improvement of the teaching methods, but also the improvement of the assessment methods. The single form of the original final closing examination has been expanded into multiple forms and fullline assessments.

First of all, for the basic theory, a detailed online assessment schemes is needed, which includes after-class testing for each knowledge point, testing for each chapter, mid-term and final testing for each semester, and total testing for the entire course.

Secondly, different assessment methods should be adopted according to different teaching contents. As for the contents of strong application, it is classified as independent innovation work. The students present in the form of works through group brainstorming, and conduct open evaluation and scoring on the Internet. Teachers and students participate together. In this form, students' participation in the course can be increased.

At the same time, the website platform of the course has a statistical function that can count student's participation in online open courses during the study, such as previewing, participation in chapter testing and discussion questions, job completion, etc. All the points are counted in the total score of the course. In this way, the process control of students' learning should be emphasized, and the enthusiasm and initiative of students should be enhanced.

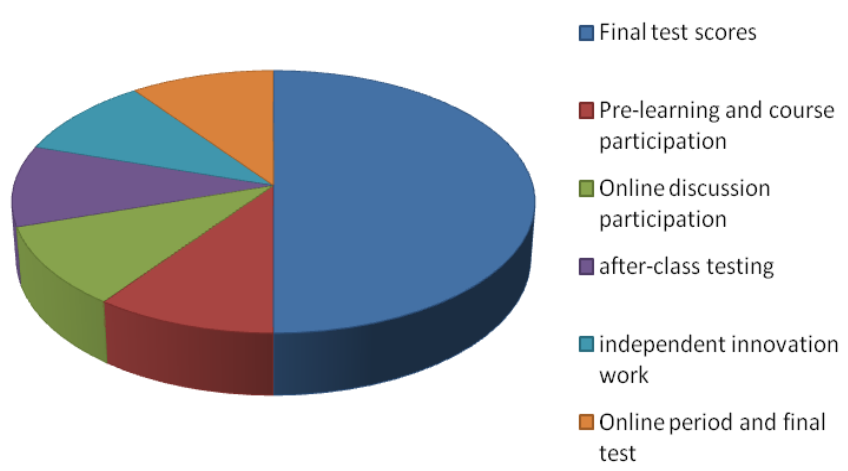

Figure 3. The score ratio of the assessment

In figure 3, the assessment method is displayed by percentage.

\section{SUMMARY}

Through a series of auxiliary learning methods, such as learning, discussing and testing online, it can effectively solve the problems that the less teaching hours, the scattered contents, and the mastery of students' knowledge is not solid. Meanwhile, the students and teachers have a good opportunity to learn and communicate.

Any course is not permanent and it is necessary to continuously improve with the development of science and technology. The dynamic development and continuous construction are also needed for online course construction. From the perspective of course teaching, the primary task of the implementation of the curriculum includes several points, which are taking the knowledge points out of the teaching content, carrying out the overall design of the subject, scientifically breaking up the knowledge, keeping the independence and relevance of the knowledge points, reflecting the essence of the curriculum in the limited teaching time, and recording the high level video, etc.

At the same time, we should always maintain a concept that the platform, technology and means should serve the content. Building a high-level teaching content is the core of the curriculum reform. The purpose of higher education is not only to impart knowledge, but more importantly, to cultivate the students' logical thinking ability, innovation and exploration ability, and the ability to accept new things. ${ }^{[3]}$

\section{ACKNOWLEDGMENT}

This research was financially supported by the teaching reform project of shanghai university of medicine \& health sciences, and the project number is JG (18)06-A3-01.

\section{REFERENCES}

[1] C. Xiaohu, "Analysis of the Connotation of Application-type Undergraduate Education and the Construction of Its Talent Cultivation System," Jiangsu Higher Education, vol. 1, pp. 86-88, 2008. 
[2] M. Yan, Y. Chao, "Research on the current situation and Countermeasures of online education in Colleges and Universities," Education in Shanxi: Higher Education, vol. 8, pp. 25-26, 2016.

[3] N. Mucui, Z. Hanzhuang, "Prospect and idea on the construction of online open physics courses group,"Colledg Physics,Vol.36, PP.5155,2017 